\section{Transforming activities of the NUP98-KMT2A fusion gene associated with myelodysplasia and acute myeloid leukemia}

\author{
James N. Fisher, ${ }^{1,2^{*}}$ Angeliki Thanasopoulou, ${ }^{1,2^{*}}$ Sabine Juge, ${ }^{1,2}$ Alexandar \\ Tzankov, ${ }^{3}$ Frederik O. Bagger, ${ }^{1,2}$ Max A. Mendez, ${ }^{1,2}$ Antoine H.F.M. Peters ${ }^{4,5}$ \\ and Juerg Schwaller ${ }^{1,2}$ \\ ${ }^{1}$ University Children's Hospital Basel (UKBB); ${ }^{2}$ Department of Biomedicine, University of \\ Basel; ${ }^{3}$ nnstitute for Pathology, University of Basel; ${ }^{4}$ Faculty of Sciences, University of \\ Basel and ${ }^{5}$ Friedrich Miescher Institute for Biomedical Research, Basel, Switzerland
}

*JNF and ATh contributed equally as co-first authors.
I nv(11)(p15q23), found in myelodysplastic syndromes and acute myeloid leukemia, leads to expression of a fusion protein consisting of the $\mathrm{N}$-terminal of nucleoporin 98 (NUP98) and the majority of the lysine methyltransferase 2A (KMT2A). To explore the transforming potential of this fusion we established inducible iNUP98-KMT2A transgenic mice. After a median latency of 80 weeks, over $90 \%$ of these mice developed signs of disease, with anemia and reduced bone marrow cellularity, increased white blood cell numbers, extramedullary hematopoiesis, and multilineage dysplasia. Additionally, induction of iNUP98-KMT2A led to elevated lineage marker-negative Sca- $1^{+}$c-Kit ${ }^{+}$cell numbers in the bone marrow, which outcompeted wildtype cells in repopulation assays. Six iNUP98-KMT2A mice developed transplantable acute myeloid leukemia with leukemic blasts infiltrating multiple organs. Notably, as reported for patients, iNUP98-KMT2A leukemic blasts did not express increased levels of the Hox $A-B-C$ gene cluster, and in contrast to KMT2A-AF9 leukemic cells, the cells were resistant to pharmacological targeting of menin and BET family proteins by MI-2-2 or JQ1, respectively. Expression of iNUP98-KMT2A in mouse embryonic fibroblasts led to an accumulation of cells in G1 phase, and abrogated replicative senescence. In bone marrow-derived hematopoietic progenitors, iNUP98-KMT2A expression similarly resulted in increased cell numbers in the G1 phase of the cell cycle, with aberrant gene expression of Sirt1, Tert, Rbl2, Twist1, Vim, and Prked, mimicking that seen in mouse embryonic fibroblasts. In summary, we demonstrate that iNUP98-KMT2A has in vivo transforming activity and interferes with cell cycle progression rather than primarily blocking differentiation.

\section{Introduction}

The gene encoding the $98 \mathrm{kDa}$ nuclear pore protein (NUP98) is recurrently involved in chromosomal translocations associated with various hematologic malignancies. Most of these translocations result in the expression of fusion genes comprising the N-terminal phenylalanine-glycine (FG)-repeats of NUP98 fused to a large group of different partners of which the homeobox family of transcription factors (such as HOXA9 or HOXD13) or non-homeobox epigenetic regulators are a part. ${ }^{1,2}$ Like NUP98, the lysine methyltransferase KMT2A, also referred to as "mixed lineage leukemia" (MLL) gene, encoding for a SET-domain histone H3K4 methyltransferase is a recurrent target of leukemia-associated chromosomal rearrangements. These generally lead to expression of fusion transcripts that contain the amino-terminal moiety of KMT2A fused to different partners, of which $A F 4, A F 9, E N L$ and $A F 10$ are among the most prevalent of the currently more than 70 known. ${ }^{3,4}$ Several KMT2A fusions have been shown to be hematopoietic oncogenes, which phenocopy the disease in vivo when expressed in murine bone mar-
Ferrata Storti Foundation

Haematologica 2020

Volume 105(7):1857-1867

\section{Correspondence:}

JUERG SCHWALLER

j.schwaller@unibas.ch

Received: March 1, 2019.

Accepted: September 24, 2019.

Pre-published: September 26, 2019.

doi:10.3324/haematol.2019.219188

Check the online version for the most updated information on this article, online supplements, and information on authorship \& disclosures: www.haematologica.org/content/105/7/1857

(C)2020 Ferrata Storti Foundation

Material published in Haematologica is covered by copyright. All rights are reserved to the Ferrata Storti Foundation. Use of published material is allowed under the following terms and conditions:

https://creativecommons.org/licenses/by-nc/4.0/legalcode. Copies of published material are allowed for personal or internal use. Sharing published material for non-commercial purposes is subject to the following conditions:

https://creativecommons. org//icenses/by-nc/4.0/legalcode, sect. 3. Reproducing and sharing published material for commercial purposes is not allowed without permission in writing from the publisher. 
row (BM). ${ }^{3-6}$ In cases in which these fusions do not contain the KMT2A-SET (suppressor of variegation 3-9, enhancer of zeste, and trithorax) domain, they acquire H3K79 or H4R3 histone methyltransferase- or acetyltransferase activity through interactions with several cofactors. ${ }^{5,6}$ The interaction between chromatin and KMT2A fusions, mediated by the N-terminal menin- and the LEDGF (lens epithelium-derived growth factor) binding domain, has been shown to be crucial for maintenance of the leukemic phenotype..$^{7-10}$ Exploration of the KMT2A-menin-LEDGF interaction triad has led to the development of a series of promising small molecules with potent antileukemic activity. ${ }^{11,12}$ More recent studies have proposed physical interactions between NUP98, and NUP98 fusion proteins, with KMT2A and non-specific lethal histone-modifying protein complexes. Parallel genetic studies using mouse models suggested that NUP98-fusion gene driven leukemogenesis might be dependent on KMT2A function. ${ }^{13-15}$

Inv $(11)(\mathrm{p} 15 \mathrm{q} 23)$ has been reported as the sole chromosomal abnormality in patients with several hematologic malignancies including myelodysplastic syndromes (MDS) and acute myeloid leukemia (AML); ${ }^{16-20}$ however, to date NUP98-KMT2A fusion expression has only been reported in two patients with AML. ${ }^{19}$ Using fluorescent in situ hybridization and reverse transcription quantitative polymerase chain reaction (PCR), Kaltenbach et al. found that inv(11)(p15q23) leads to fusion of the NUP98-FGrepeats to almost the entire $K M T 2 A$ open reading frame (ORF). ${ }^{19}$ In this case, exon 1 encoding for the $\mathrm{N}$-terminal menin-LEDGF interaction domain is lost. In contrast to other KMT2A- or NUP98-fusion associated diseases, NUP98-KMT2A+ leukemic blasts did not express known KMT2A targets such as the HOXA-gene cluster (HOXA5, HOXA7, HOXA9, or HOXA10) suggesting alternative mechanisms of transformation. As the size of the NUP98KMT2A fusion ORF ( $>12 \mathrm{~kb}$ ) limits the ability to test its transforming activity by retroviral expression in BM cells, we generated an inducible transgenic mouse model. We found that iNUP98-KMT2A expression led to a symptomatic $^{21}$ hematologic disease mimicking human MDS or AML that, as in patients, was not associated with elevated expression of the Hox-A-B-C gene cluster. ${ }^{19}$ Thus, our work formally proves that a fusion, in which the N-terminus of KMT2A is replaced by the FG-repeats of NUP98, is a leukemogenic oncogene.

\section{Methods}

\section{Primary induction of iNUP98-KMT2A expression}

Adult transgenic mice were provided with doxycyclineimpregnated chow pellets (400 ppm Doxycycline Diet, HarlanTeklad) ad libitum from 6-8 weeks of age until analysis. All experiments were conducted in compliance with Swiss animal welfare laws and were approved by the Swiss Cantonal Veterinary Office of Basel Stadt.

\section{Flow cytometry, colony-forming assays and cell culture}

Total BM cells were isolated from wildtype (WT) C57BL/6 and iNUP98-KMT2A mice and processed with the Direct Lineage Cell Depletion kit (Miltenyi Biotec, Bergisch Gladbach, Germany). For immunophenotypic analysis, cells were incubated with antibodies recognizing the mouse lineage markers: CD11b (Mac-1), Ly-6G (Gr-1), CD117 (c-Kit), FcyRII/III, Ter119,
CD71, B220, CD3, and CD34. For lineage marker-negative Sca$1^{+} \mathrm{c}-\mathrm{Kit}^{+}(\mathrm{LSK})$ characterization, lineage marker negative (Lin) BM cells were stained with Ly-6A/E (Sca-1), c-Kit, CD150 (SLAM1) and CD48, as well as CD45.1 and CD45.2 antibodies.

For proliferation experiments, $1 \times 10^{5}$ Lin $^{-} \mathrm{BM}$ cells were cultured in liquid media containing murine stem cell factor $(100$ $\mathrm{ng} / \mathrm{mL})$, murine interleukin $3(6 \mathrm{ng} / \mathrm{mL})$, human interleukin 6 (10 $\mathrm{ng} / \mathrm{mL})$ and doxycycline $(1 \mu \mathrm{g} / \mathrm{mL})$. For colony-forming assays, $5 \times 10^{3}$ Lin cells were plated in $2 \mathrm{~mL}$ of methylcellulose (MethoCult M3434, StemCell Technologies, Vancouver, Canada) and counted after 8-10 days. For cell cycle analysis, cells were fixed for $16 \mathrm{~h}$ at $4{ }^{\circ} \mathrm{C}$ in a $4 \%$ paraformaldehyde solution (Thermo Scientific, Monza, Italy) then stained with Hoechst 33342 (Invitrogen, Waltham, USA) and pyronin Y (Sigma, St. Louis, USA) for $40 \mathrm{~min}$ at room temperature, flowed for $15 \mathrm{~min}$ on ice, before washing in FACS buffer and analysis. For in vitro experiments, unless indicated otherwise, doxycycline was used at a concentration of $1 \mu \mathrm{g} / \mathrm{mL}$.

\section{P0-PRO-1 and 7-aminoactinomycin D staining of apop- totic cells}

Apoptotic cells were quantified using the PO-PRO-1 and 7aminoactinomycin D staining kit (Invitrogen, Waltham, USA) in accordance with the kit protocol.

\section{Expression analysis of senescence-related genes in iNUP98-KMT2A mouse embryonic fibroblasts}

Mouse embryonic fibroblasts (MEF) were generated by isolation of E14.5 embryos from iNUP98-KMT2A mice and the genotype was checked by PCR. To investigate senescence, WT and iNUP98-KMT2A MEF were grown in Dulbecco modified Eagle medium with doxycycline and serially passaged into $100 \mathrm{~mm}$ plates when $90 \%$ confluence was reached. $\beta$-Galactosidase staining was performed using the Senescence $\beta$-Galactosidase Staining kit (Cell Signaling, Leiden, the Netherlands) when WT MEF started showing signs of senescence. RNA was extracted from MEF cell pellets at early and late passages and senescencerelated gene expression was analyzed by quantitative real-time PCR using a commercially available kit (RT2 Profiler PCR Array, OIAGEN AG, Hombrechtikon, Switzerland) (Online Supplementary Table S2) as well as by manual quantitative PCR using specific primers. Gene expression levels on the $\mathrm{RT}^{2}$ Profiler PCR Array were normalized to an internal panel of housekeeping genes, whereas individual quantitative PCR data were normalized to Gapdh.

\section{Exposure of leukemic blasts to menin and BET inhibitors}

iNUP98-KMT2A and KMT2A-AF9 leukemic blasts were isolated and treated for $48 \mathrm{~h}$ in vitro with $0-500 \mathrm{nM}$ of the $\mathrm{BRD} 4$ inhibitor JQ1/vehicle (dimethylsulfoxide, DMSO) or 0-12 $\mu \mathrm{M}$ of the menin-interaction inhibitor MI-2-2/vehicle (DMSO). Cell cycle analysis was performed at the $48 \mathrm{~h}$ time-point after staining with Hoechst 33342 and pyronin $Y$ as described above.

\section{Results}

\section{Establishing iNUP98-KMT2A transgenic mice}

To address the transforming potential of NUP98KMT2A, we cloned a full-length human fusion ORF into the p2LOX targeting-vector to integrate it into the Hprt gene locus on the X-chromosome under the control of a doxycycline-responsive element in embryonic stem cells. A reverse Tet transactivator ( $r t T A)$ stably integrated in the 
Rosa26 locus allows doxycycline-regulated transgene expression (Figure 1A). ${ }^{19,22,23}$ We used primarily female mice to mitigate the effects of any potential sex-related differences in transgene expression.

\section{Induction of iNUP98-KMT2A results \\ in an myelodysplastic syndrome-like disease in vivo}

Primary-induced iNUP98-KMT2A mice developed signs of distress after a variable latency of 13-106 weeks (median latency $=80$ weeks, $n=22$ ) (Figure 1B). Blood values from non-induced iNUP98-KMT2A mice did not differ significantly from those of WT mice (Online Supplementary Figure $S 1 A)$. We also explored disease induction by transplanting total BM from naïve (off doxycycline) iNUP98-KMT2A mice into lethally irradiated syngenic WT mice. In comparison to primary-induced mice, BM transplant recipient animals developed the symptoms earlier (median latency $=32$ weeks, $P=0.0007$, log-rank test, $\mathrm{n}=5$ ) (Figure 1B, Online Supplementary Table S3).

Most symptomatic primary-induced iNUP98-KMT2A mice had peripheral blood counts in the normal range with slightly increased numbers of white blood cells, and reticulocytes. Decreases were seen in hemoglobin levels and red blood cell numbers $(P=0.049$, unpaired $t$-test, $\mathrm{n}=15$ ) (Figure 1C). Blood values from iNUP98-KMT2A $\mathrm{BM}$ transplant recipients revealed a similar trend to those of primary-induced samples in all parameters analyzed with significantly increased numbers of white blood cells $(P=0.0006$, unpaired $t$-test, $\mathrm{n}=5)$ and reduced cellular hemoglobin levels ( $P=0.03$, unpaired $t$-test, $\mathrm{n}=5)$. Notably, the overall cellularity of the BM of primary-induced mice was reduced ( $P=0.0099$, unpaired $t$-test, $n=9)$ relative to controls. Further analysis of different BM subpopulations revealed decreased numbers of myeloid cells (Mac-1+/Gr$\left.1^{+}\right)$, B cells $\left(B 220^{+}\right)$, and $\mathrm{T}$ cells $\left(\mathrm{CD}^{+}\right)$(Online Supplementary Figure S1B). Signs of intramedullary apoptotic cell death was found in some but not all mice as measured by combined PO-PRO-1 and 7-aminoactinomycin D staining (Figure 1C) with non-significant increased apoptosis of CD71+Ter119+, but not of myeloid $\left(\mathrm{Mac}^{-} 1^{+}, \mathrm{Gr}-1^{+}\right)$or lymphoid $\left(\mathrm{CD}^{+} / \mathrm{CD}^{+} / \mathrm{B}^{2} 20^{+}\right)$cells from primary-induced animals relative to WT controls (Online Supplementary Figure S1C). In primary induced mice we occasionally observed signs of dysplasia on blood smears, with the appearance of bi-lobed myeloid cells and polychromatophilic reticulocytes (Figure 1D) as well as signs of extramedullary hematopoiesis in the spleen and the liver (Figure 1E).

The BM of iNUP98-KMT2A mice that had been on doxycycline for several months displayed rather heterogeneous immunophenotypes: some showed an increase in Mac$1^{+} / \mathrm{Gr}-1^{+}$cells, whereas others showed a marked decrease in mature myeloid cells with concomitant increases in FcyRII/III ${ }^{+}$and c-Kit populations (Figure 1F, G).

To address potential reversibility, we transplanted iNUP98-KMT2A BM cells into lethally-irradiated WT recipients on doxycycline: upon development of symptoms in the first mouse, we reverted to non-doxycycline chow and followed the remaining mice for several months. Diseasefree survival was significantly increased by the removal of doxycycline food (median latency $=49$ weeks, $P=0.002$, logrank test, $\mathrm{n}=6$ ) (Figure $1 \mathrm{~B}$ ) although analysis of peripheral blood at death revealed that many parameters remained similar to those of BM transplant recipients on doxycycline until death (Figure 1C).
Collectively, these data show that transgenic expression of iNUP98-KMT2A alters the hematopoietic system in vivo: there were increases in the numbers of white blood cells and apoptotic cells, and decreases in hemoglobin and the numbers of red blood cells and cells in the BM with signs of extramedullary hematopoiesis and morphological signs of dysplasia with some interindividual differences.

\section{Expression of iNUP98-KMT2A leads to expansion and competitive advantage of hematopoietic stem and progenitor cells}

We next studied the impact of iNUP98-KMT2A expression on the cellular hierarchy of the BM. We found that prior to developing symptoms (mean time on doxycycline: 36 weeks), iNUP98-KMT2A mice displayed an expansion of Lin $\mathrm{Sca}-1^{+} \mathrm{c}-\mathrm{Kit}^{+}$(LSK) hematopoietic stem and progenitor cells (HSPC) $(P=0.04$, unpaired $t$-test, $n=4)$ (Figure 2A, Online Supplementary Figure S1D). Further breakdown of the LSK compartment revealed no significant changes in the relative distribution of CD34 long-term hematopoietic stem cells, and $\mathrm{CD}^{+} 4^{+}, \mathrm{CD}^{+} 8^{+}, \mathrm{CD} 150^{-}$multipotent progenitors (Figure 2B). Interestingly, we found that iNUP98-KMT2A LSK, but not mature cells, from asymptomatic mice (mean time on doxycycline: 55 weeks) were cycling more than control cells as shown by a reduced fraction of quiescent cells in $\mathrm{G}_{0}$ phase $(P=0.0098$, unpaired $t$-test, $\mathrm{n}=3)$ and an increase in the $G_{1}$ fraction (Figure $2 \mathrm{C}$, Online Supplementary Figure S1E).

To address the functional consequence of the increased LSK number in iNUP98-KMT2A mice on doxycycline, we performed competitive repopulation assays. Naïve CD45.2+ iNUP98-KMT2A or WT (CTRL) total BM cells were transplanted 1:1 with CD45.1+ WT total BM cells into lethallyirradiated CD $45.1^{+}$WT recipients (on doxycycline) and the cellular chimerism in the peripheral blood was determined 4, 8, 12, 18, and 25 weeks after transplantation. We observed that the proportion of CD45.2+ iNUP98-KMT2A cells in the peripheral blood steadily increased over time (Figure 2D) whereas the chimerism in mice that received CD 45.2+ WT BM cells did not change significantly, remaining near to $50 \%$. The percentage of iNUP98-KMT2A CD 45.2 $2^{+}$cells was initially lower than that of CTRL (WT) $(P=0.0153$, $t$-test, $n=5)$. After 18 weeks, CD45.2+ iNUP98KMT2A cell numbers had increased by 1.6 -fold compared to week $4(P=0.034$, $t$-test, $\mathrm{n}=5)$ and by 25 weeks CD $45.2^{+}$ iNUP98-KMT2A cell numbers had further increased relative to initial measurements $(P=0.004, t$-test, $n=5)$ and were $20 \%$ greater than CD $45.2^{+}$WT cells at the same time-point $[P=0.019,2$-way analysis of variance (ANOVA), $\mathrm{n}=4]$. Interestingly, iNUP98-KMT2A CD45.2 ${ }^{+}$cells contributed to a greater extent to the myeloid lineage $\left(\mathrm{Gr}-1^{+}\right)$and the $\mathrm{B}$ lineage $\left(\mathrm{B} 220^{+}\right)$but equally to the $\mathrm{T}$ lineage $\left(\mathrm{CD}^{+}\right)$, compared to WT controls (Figure 2E). Transplantation of total BM from primary recipients into lethally-irradiated CD45.1 secondary recipients resulted in a heterogeneous outcome: in two mice ("M1" \& "M2") the BM was dominated by CD45.2 cells, while two other mice ("M4" \& "M5") showed predominantly CD45.1+ cells. One mouse ("M3") developed a CD45.2+ AML 23 weeks after transplantation (Figure 2F).

\section{Some iNUP98-KMT2A mice develop transplantable acute myeloid leukemia}

After a median latency of 62 weeks, six out of 22 iNUP98-KMT2A mice on doxycycline developed a 
A

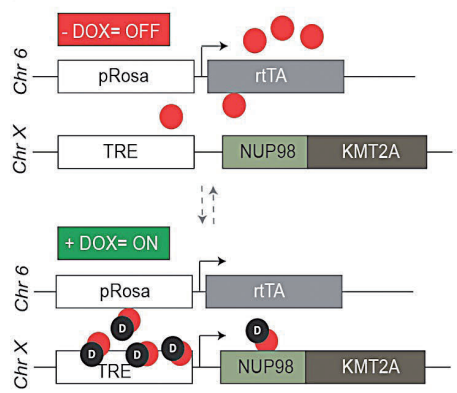

B

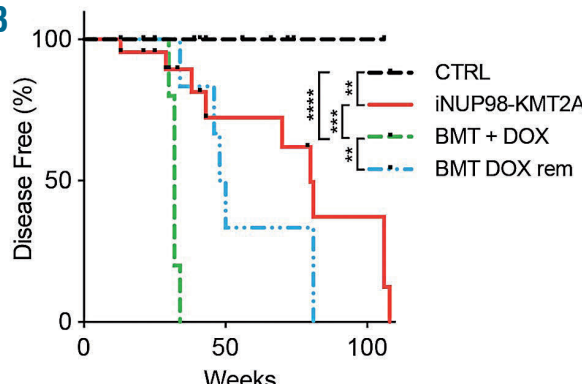

C

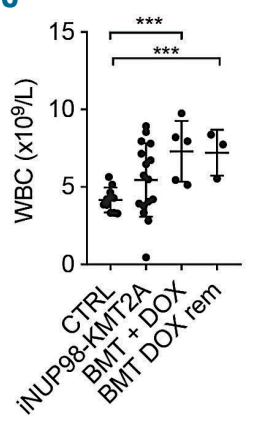

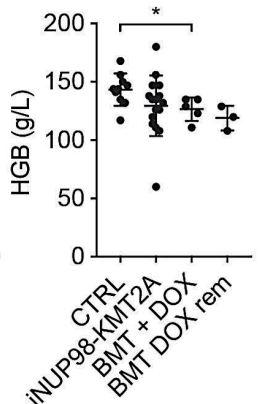

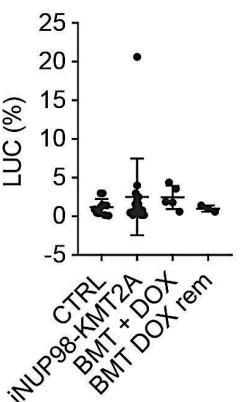

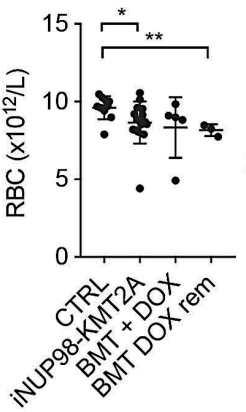

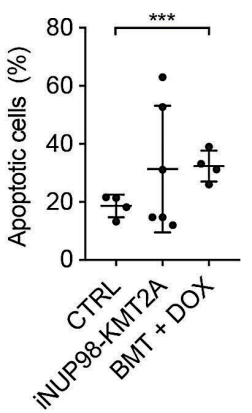

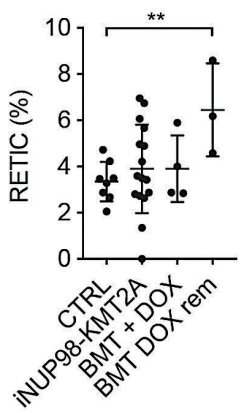

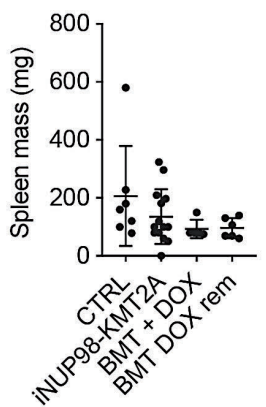

D
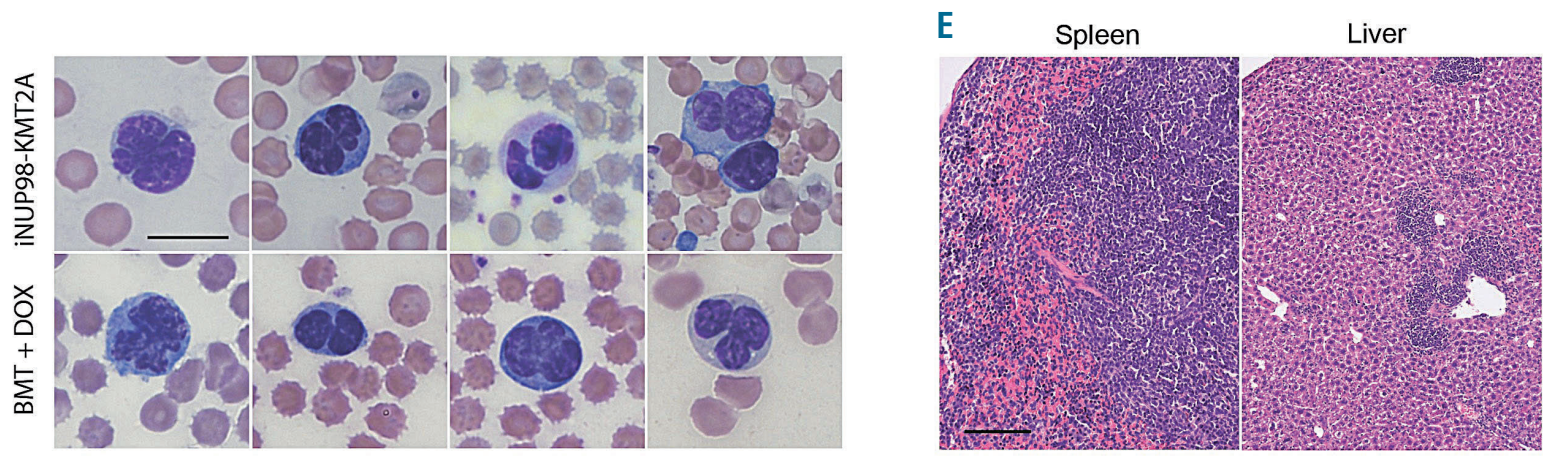

$\mathbf{F}$

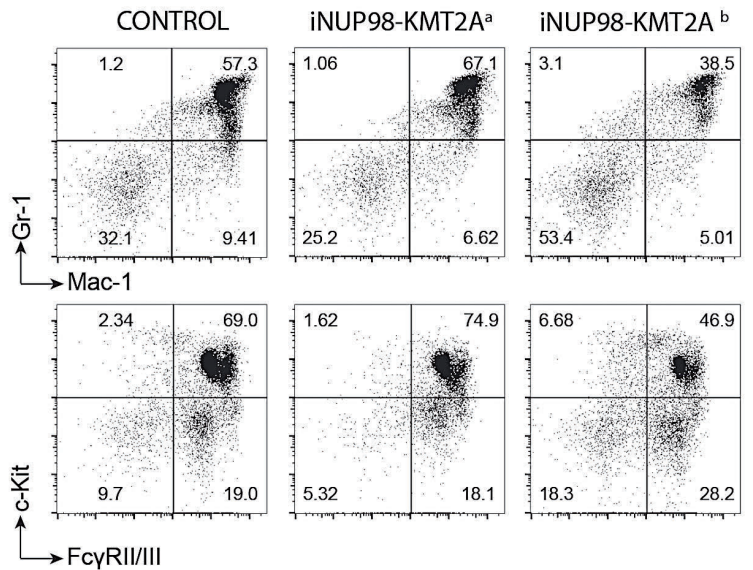

G $\quad$ BMT no DOX $\quad$ BMT + DOX a $\quad$ BMT + DOX ${ }^{\text {b }}$
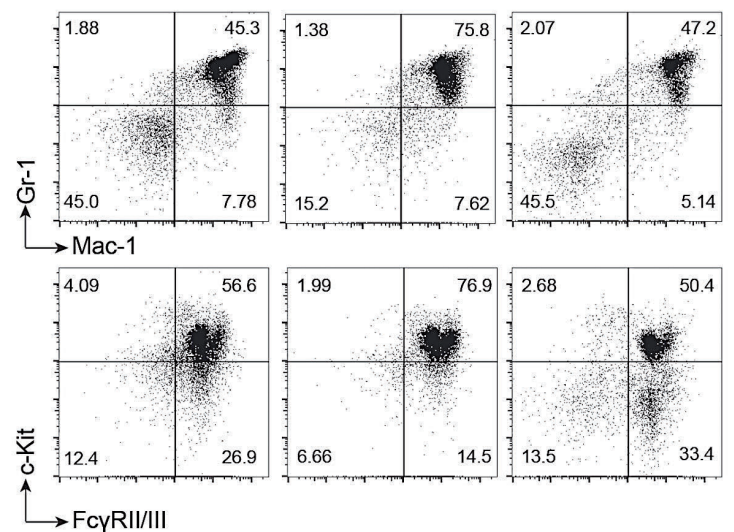

Figure 1. Expression of iNUP98-KMT2A leads to development of a myelodysplastic syndrome-like disease in transgenic mice. (A) iNUP98-KMT2A mice contain a reverse Tet transactivator (rtTA) element in the Rosa26 gene locus on chromosome 6 (Chr 6), and a human NUP98-KMT2A open reading frame after a TET-responsive element (TRE) in the Hprt locus on the X-chromosome (Chr X). Administration of the tetracycline analog, doxycycline (DOX) leads to expression of the NUP98-KMT2A fusion construct. (B) Kaplan-Meier curves for DOX-exposed primary-induced adult (6-10 weeks) iNUP98-KMT2A mice and wildtype (WT) littermates (CTRL), as well as adult WT irradiated recipients of iNUP98-KMT2A total bone marrow transplants (BMT) exposed to DOX (BMT + DOX) and BMT recipients taken off DOX (BMT DOX rem) after 31 weeks. $* P<0.05, * * P<0.01, * * * P<0.001, * * * * P<0.0001$, log-rank test. (C) Blood values from DoX-exposed adult iNUP98-KMT2A mice and WT littermates (CTRL), as well as adult WT irradiated recipients of iNUP98-KMT2A total BMT exposed to DOX (BMT + DOX) and BMT recipients taken off DOX (BMT DOX rem) after 31 weeks. $\star P<0.05$, $* * P<0.01$, $* * * P<0.001$, unpaired $t$-tests. WBC: white blood cells; RBC: red blood cells; HGB: hemoglobin; LUC: abnormal leukocytes. (D) Dysplastic immature myeloid cells on peripheral blood smears of pre-leukemic DOX-induced iNUP98-KMT2A mice as well as WT recipients of iNUP98-KMT2A total BMT on DOX. Scale bar: 10 um. (E) Histopathology sections of DOX-exposed iNUP98-KMT2A mice show extramedullary hematopoiesis in the spleen and liver. Scale bar: $100 \mu \mathrm{m}$. (F) Immunophenotype (Mac1, Gr-1, FcyRII/III and c-Kit, given in \%) of total bone marrow cells from pre-leukemic iNUP98-KMT2A mice. The flow plots are representative of three mice/group. (G) Immunophenotype (Mac-1, Gr-1, FcyRII/III and c-Kit, given in \%) of total bone marrow cells from WT mice transplanted with iNUP98-KMT2A bone marrow on DOX. Mice exhibited two diverse phenotypes; denoted $a$ and $b$. Transplanted mice off DOX were used as the negative control. 

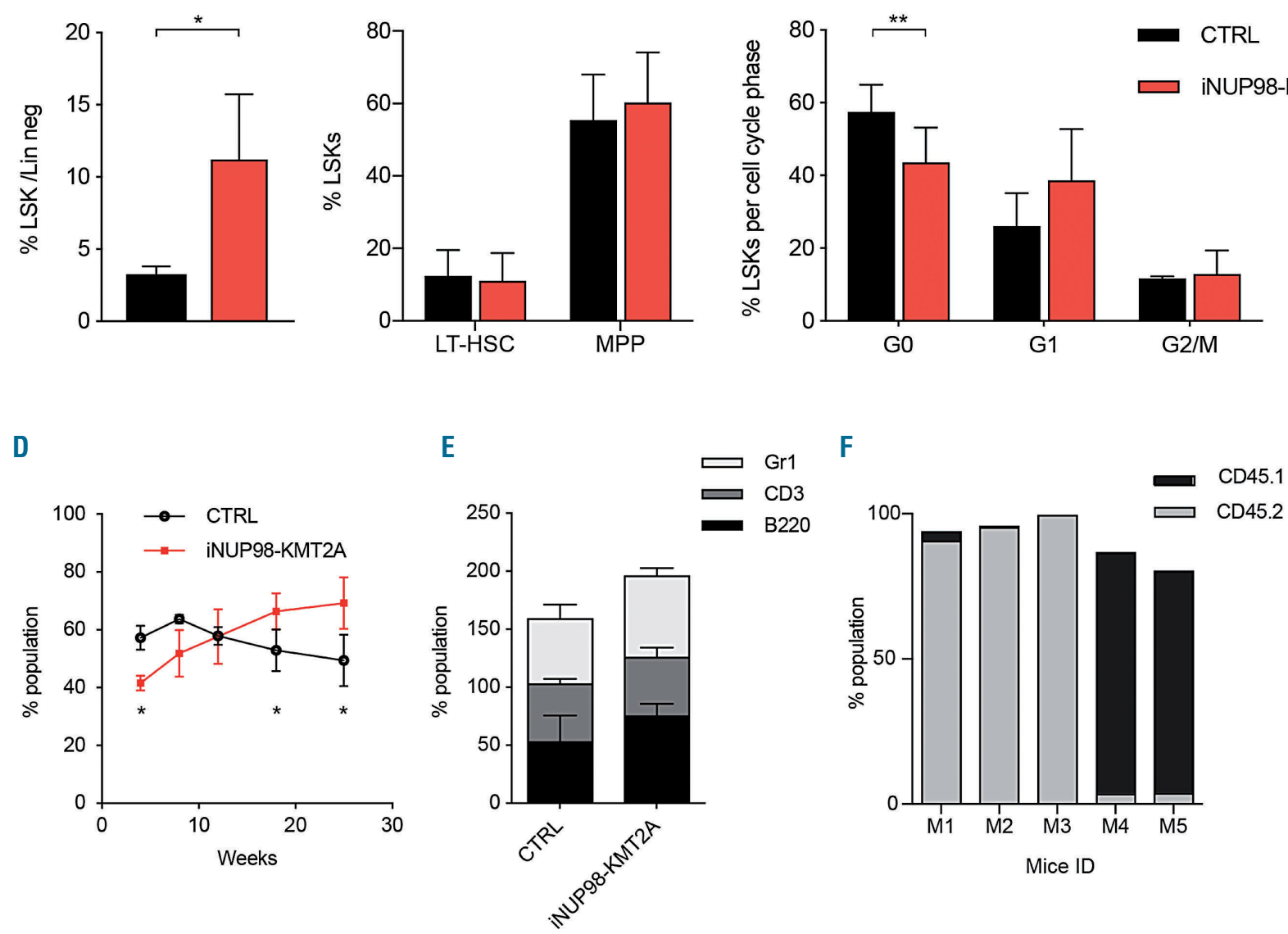

Figure 2. Expression of iNUP98-KMT2A results in LSK cell expansion with a competitive repopulation advantage. (A) Lineage negative (Lin) bone marrow (BM) cells from pre-leukemic iNUP98-KMT2A mice and wildtype (WT) littermate controls (CTRL) were stained for c-Kit and Sca-1 and analyzed by flow cytometry. *P<0.05, unpaired $t$-test. (B) Lin BM from pre-leukemic iNUP98-KMT2A mice and WT littermate controls were stained for markers of long-term hematopoietic stem cells (LTHSC) (LSK, CD150', CD48) and multipotent progenitors (MPP) (LSK, CD34 ${ }^{+}, C_{4} 8^{+}$, CD150) and analyzed by flow cytometry. The percentages of LSK identified as LT-HSC and MPP are shown. (C) Cell cycle analysis of LSK from pre-leukemic iNUP98-KMT2A mice and WT littermate controls. $* * P<0.01$, unpaired $t$-test. (D) Competitive repopulation assay: lethally-irradiated CD45.1 WT recipients were transplanted with a 1:1 mixture of total BM cells from CD45.2 iNUP98-KMT2A and CD45.1 WT mice in the presence of doxycycline (DOX). The percentage of CD45.2 cells present in the peripheral blood was measured by flow cytometry over a period of 25 weeks. $* P<0.05$, unpaired $t$-test. (E) At week 25 of the competitive repopulation assay, the CD45.2 $2^{+}$cells were analyzed for percentages of Gr-1, CD3, and B220 markers. (F) Cellular BM chimerism of WT CD45.1 mice 25 weeks after competitive transplantation with CD45.2 ${ }^{+}$iNUP98-KMT2A BM. All mice were exposed to DOX throughout the experiment.

leukemic phenotype characterized by the presence of leukemic blasts on peripheral blood smears, and extensive leukemic infiltration in the BM, spleen, liver and lungs (Figure 3A, Online Supplementary Figure S2A). This was accompanied by significantly increased white blood cell counts $(P=0.0018$, unpaired $t$-test, $\mathrm{n}=5)$ and abnormal leukocytes ("LUC") ( $P=0.0468$, unpaired $t$-test, $n=5)$ counts in the periphery and splenomegaly (Figure $3 \mathrm{~B}$, Online Supplementary Table S4). Immunophenotypic analysis of highly-infiltrated BM revealed intermediate to high expression levels of myeloid markers Mac-1, Gr-1, and FcyRII/III in five out of six mice, with baseline expression of B220 and CD3 lymphoid markers characterizing the disease as AML (Figure 3C, Online Supplementary Figure S2B-D).

Transplantation of total BM from diseased mice into sublethally-irradiated WT mice induced disease in 100\% of recipients. Whereas disease development was fully doxycycline-dependent upon transplantation of AML cells from one donor ("M1") (median latency 28 weeks, $P=0.025$, log-rank test, $\mathrm{n}=4$ ), leukemic cells from another donor ("M2") resulted in disease in all recipients regardless of doxycycline administration, with a similar latency (26-37 weeks) to that of recipients of "M1" cells on doxycycline (Figure 3D). Flow cytometric analysis of BM samples from transplanted leukemic mice revealed heterogeneity in $\mathrm{M} 1$ ("M1a" \& "M1b") BM recipients, including a marked doxycycline-dependent increase in $\mathrm{CD}^{+}$cells, but a consistent myeloid phenotype in recipients of $\mathrm{M} 2$ (Figure 3E).

Given the long latency to develop primary disease, we explored whether additional genotoxic insults might accelerate disease induction. Indeed, sublethal $\gamma$-irradiation (1x 600 cGy) of asymptomatic 3- to 4-week old iNUP98-KMT2A mice on doxycycline resulted in earlier onset of disease symptoms than that observed in sublethally-irradiated WT mice (median latency 26 weeks vs. undefined; $P=0.032$, log-rank test, $\mathrm{n}=5$ ) (Figure $3 \mathrm{~F}$, Online 
A

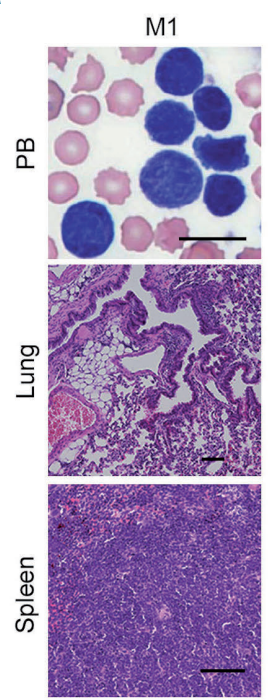

C

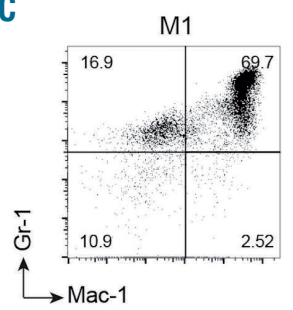

D

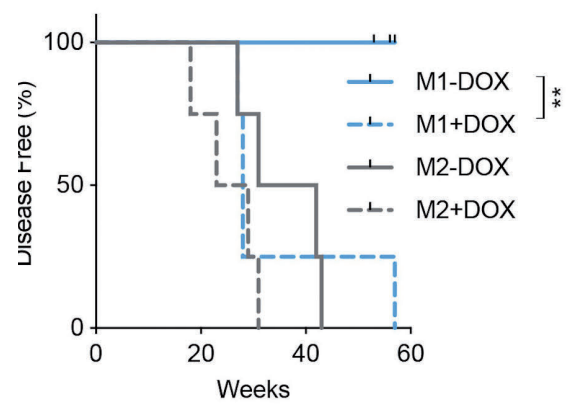

F

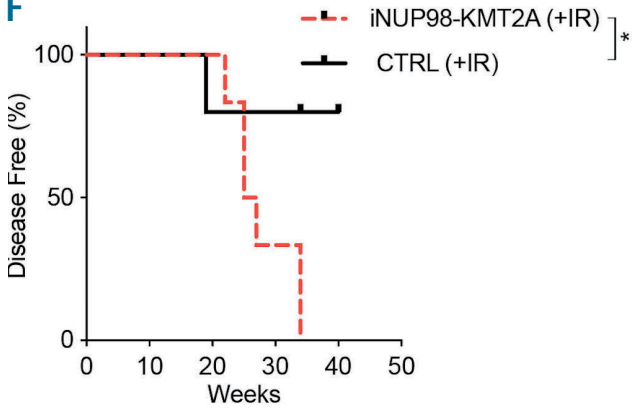

B
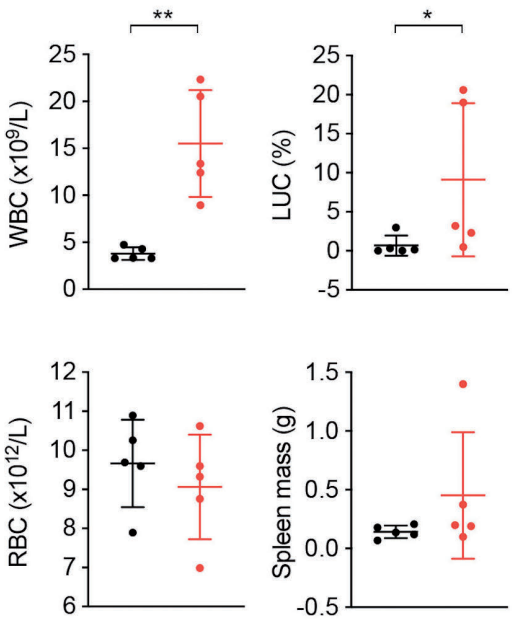

- CTRL

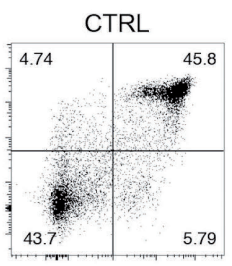

E

DOX
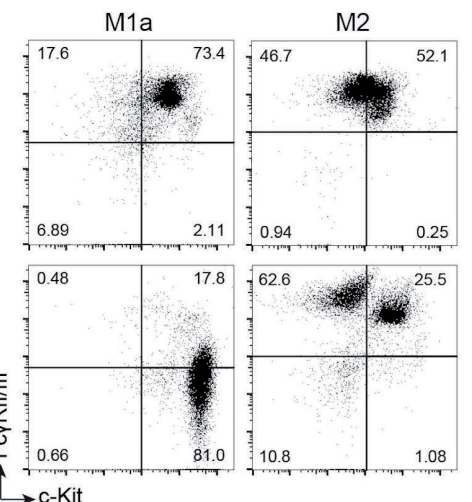

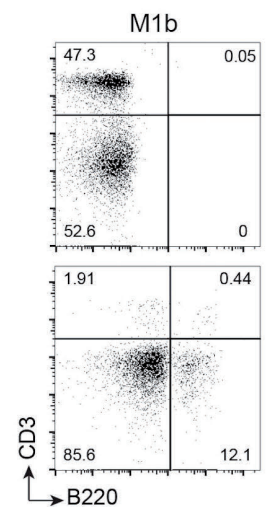

G

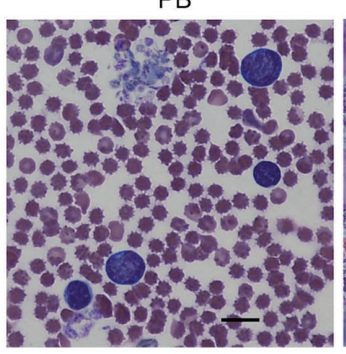

BM

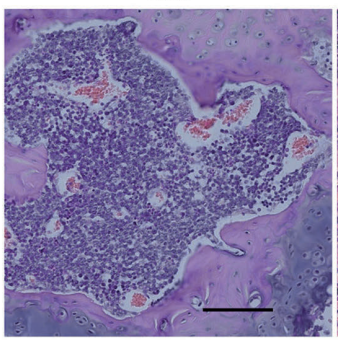

Kidney

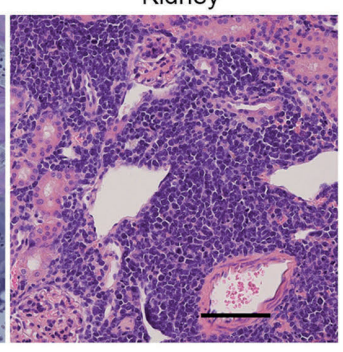

Figure 3. Expression of iNUP98-KMT2A induces a transplantable acute myeloid leukemia in some mice. (A) Histological sections and peripheral blood (PB) smears from four leukemic iNUP98-KMT2A mice. Scale bar: $10 \mathrm{um}$. (A) Blood values from doxycycline (DOX)-treated iNUP98-KMT2A mice which developed symptoms of leukemia as well as wildtype (WT) littermate controls (CTRL). ${ }^{*} P<0.05, * * P<0.01$, unpaired $t$-test, $\mathrm{n}=5$. WBC: white blood cells; LUC: abnormal leukocytes; RBC: red blood cells. (C) Gr-1 and Mac-1 expression on total BM cells from leukemic iNUP98-KMT2A mice and a representative control mouse. (D) Total BM from leukemic mice M1 and M2 was transplanted into WT recipients in the presence or absence of DOX. Kaplan-Meier curves show disease-free survival of transplanted animals. $* \star P<0.01$, log-rank test. (E) Representative immunophenotypes of total BM of recipients (on DOX) (from Figure 3D) either transplanted with iNUP98-KMT2A acute myeloid leukemia from mouse M1: M1a and M1b; or from mouse M2. (F) iNUP98-KMT2A mice were exposed to DOX $48 \mathrm{~h}$ prior to sublethal irradiation (600 cGy). Irradiated (IR) WT mice were used as controls. Kaplan-Meier curves illustrate disease-free survival. $* P<0.05$, log-rank test. (G) Representative histopathology section of a symptomatic irradiated iNUP98-KMT2A mouse. The BM is infiltrated with blasts which are also visible in the peripheral blood (PB) and kidney. Scale bars: PB: $10 \mu \mathrm{m}$; BM \& kidney: $100 \mu \mathrm{m}$. 
Supplementary Table S5) and that seen in our cohort of primary-induced, non-irradiated iNUP98-KMT2A mice on doxycycline (median latency 26 vs. 80 weeks; $P=0.0003$, log-rank test, $\mathrm{n}=6$ ) (Online Supplementary Figure 3A). All symptomatic mice had extensive multi-organ infiltration by leukemic blasts, which were visible on peripheral blood smears as well as in the BM and kidneys (Figure $3 \mathrm{G})$. Collectively, these data show that expression of iNUP98-KMT2A leads to an MDS-like disease and in some cases to transplantable AML in mice.

\section{Expression of iNUP98-KMT2A results in aberrant cell cycle progression and escape from senescence}

In the presence of doxycycline $(1 \mu \mathrm{g} / \mathrm{mL})$, ex vivo proliferation of Lin iNUP98-KMT2A BM cells was significantly impaired in liquid culture containing cytokines (murine stem cell factor, interleukin-6, and interleukin-3 (Online Supplementary Figure S3B). Expression of iNUP98-KMT2A was verified on day 6 of the culture (Online Supplementary Figure S3C). However, iNUP98-KMT2A expression did not significantly alter the clonogenic growth of BM cells in methylcellulose containing doxycycline (Online Supplementary Figure S3D). Cell cycle analysis of Lin iNUP98-KMT2A BM cells challenged with doxycycline in vitro revealed an increase in the number of cells in $G_{1}$ phase $(P=0.033$, unpaired $t$-test, $\mathrm{n}=3)$ at the expense of $\mathrm{G}_{0}$ and $\mathrm{G}_{2} / \mathrm{M}$ phases $(P=0.049$, unpaired $t$-test, $\mathrm{n}=3$ ) (Online Supplementary Figure S3E), similar to what was observed in LSK from iNUP98-KMT2A mice on doxycycline (Figure 2C).

To further explore the impact of iNUP98-KMT2A expression on cell cycle regulation we established MEF. We first verified iNUP98-KMT2A expression in the MEF (Figure 4A). We then determined cell cycle progression of iNUP98-KMT2A MEF on doxycycline and found accumulation of the cells in the $G_{1}$ phase $(P=0.081$, unpaired $t$ test, $n=3$ ) with a significant reduction of the percentage of cells in the $\mathrm{G}_{2} / \mathrm{M}$ phase $(P=0.029$, unpaired $t$-test, $\mathrm{n}=3)$ (Figure 4B). Initially, both iNUP98-KMT2A and WT MEF grew at similar rates; however, upon serial propagation of the cells we observed reduced growth of WT MEF with signs of senescence (visualized by X-gal staining for senescence-associated $\beta$-galactosidase activity) after 10 13 passages (Figure 4C, Online Supplementary Figure S3F, $G)$. In contrast, iNUP98-KMT2A MEF continued to grow at an increased rate $(P=0.0156$, Wilcoxon matched-pairs signed rank test, $n=2$ ) up to, and beyond, passage 40 . To understand how iNUP98-KMT2A MEF escape senescence, we compared the expression of 84 genes related to cell cycle regulation and senescence using a commercial array-based reverse transcription PCR assay. Combining two independent experiments revealed no significant changes in gene expression at an early time-point (passage 1) (Figure 4D) while the levels of expression of eight genes were significantly reduced in iNUP98-KMT2A MEF relative to WT MEF at later passages (passage 10-13) (Figure 4E).

Genes that were found to be dysregulated in late-passage iNUP98-KMT2A MEF samples were further analyzed in iNUP98-KMT2A HSPC, which had been exposed to doxycycline in vitro for $48 \mathrm{~h}$. Expression patterns observed in MEF for Sirt1, Rbl2, Twist1, Prked, Vim, and Tert were found to be similar in iNUP98-KMT2A HSPC, demonstrating common patterns of gene regulation in $\mathrm{MEF}$ and primary iNUP98-KMT2A cells (Figure 4F).
INUP98-KMT2A+ acute myeloid leukemia cells do not express the HoxA-B-C gene cluster and are resistant to compounds targeting the KMT2A-menin interaction

In contrast to other NUP98 fusions, primary patients' NUP98-KMT2A AML cells were shown to express reduced levels of the $H O X A-B-C$ gene cluster. ${ }^{19}$ Likewise, leukemic blasts from diseased iNUP98-KMT2A mice generally expressed very low levels of HoxA5, HoxA9, HoxA10, HoxB4, HoxB6, HoxC6 and HoxC9 mRNA compared to normal BM cells or to leukemic blasts transformed by retroviral KMT2A-ENL (rKMT2A-ENL) or the $r K M T 2 A-A F 9$ fusion genes (Figure $5 \mathrm{~A}) .^{24}$

The lack of KMT2A exon 1 encoding for the very $\mathrm{N}$-terminus, which mediates the menin/LEDGF interaction, predicts that cells carrying the NUP98-KMT2A fusion protein would be resistant to small molecule menin inhibitors. However, if leukemic transformation by NUP98 fusions depends on KMT2A, as suggested by recent studies, ${ }^{14,25}$ NUP98-KMT2A leukemic blasts might be susceptible to inhibition by small molecules targeting critical KMT2A functional interactions. To address this question, we exposed cells from two leukemic iNUP98KMT2A mice ("M1" \& "M3") to different doses of the small molecule menin inhibitor (MI-2-2) and to a bromodomain inhibitor blocking BET-family proteins including BRD4 (JO1) previously shown to efficiently block KMT2A and KMT2A-fusion controlled transcription. ${ }^{26}$ As shown in Figure 5B, MI-2-2 (3-12 $\mu \mathrm{M})$ did not impair growth of iNUP98-KMT2A leukemic blasts but at $6 \mu \mathrm{M}$ and $12 \mu \mathrm{M}$ induced a $\mathrm{G}_{1}$ cycle arrest in leukemic cells expressing the rKMT2A-AF9 fusion $(P<0.0001$, two-way ANOVA, $n=2)$, with a concomitant decrease in the proportion of cells in the $S$-phase $(P<0.0001$, two-way ANOVA, $\mathrm{n}=2)$ and in the $\mathrm{G}_{2} / \mathrm{M}$-phase $(6 \mu \mathrm{M}: P=0.0246$; $12 \mu \mathrm{M}: P=0.0144$, two-way ANOVA, $\mathrm{n}=2)$. Exposure of iNUP98-KMT2A cells to low (0.05-0.5 $\mu \mathrm{M})$ doses of JQ1 did not induce cell cycle arrest or significant cytotoxicity as seen in rKMT2A-AF9 cells (Figure 5C), but increased the fraction of cells in the $G_{1}$ phase of the cycle, suggesting alternative transforming mechanisms of NUP98KMT2A compatible with a defective cell cycle checkpoint control.

\section{Discussion}

$\operatorname{Inv}(11)(p 15 q 23)$ has been reported in a heterogeneous group of human hematologic malignancies including MDS, AML, peripheral T-cell lymphoma, childhood acute lymphoblastic acute leukemia, myeloma and hairy cell leukemia. ${ }^{20}$ In the majority of the myeloid cases, $\operatorname{inv}(11)(\mathrm{p} 15 \mathrm{q} 23)$ was the sole cytogenetic abnormality, suggesting a role as a leukemogenic driver. Expression of a NUP98-KMT2A fusion gene has so far been reported in two AML patients with inv(11)(p15q23). ${ }^{19}$ Detailed molecular work-up of additional patients is needed to delineate the epidemiology of this rare entity. Notably, inv(11)(p15q23) was also found in some solid cancers but never analyzed in more detail. ${ }^{20}$ To determine the transforming potential of the NUP98-KMT2A fusion gene we developed inducible transgenic mice. This approach avoids some of the drawbacks of retroviral gene transfer such as cooperating integration events or transduction bias of early myeloid progenitor cells. In addition, the large size of the NUP98-KMT2A fusion ORF would clear- 
A

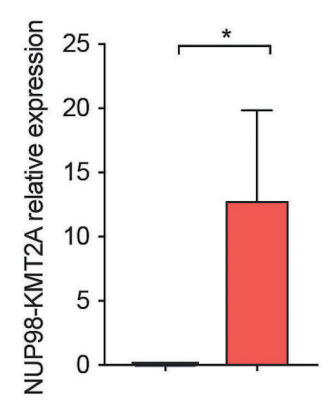

B

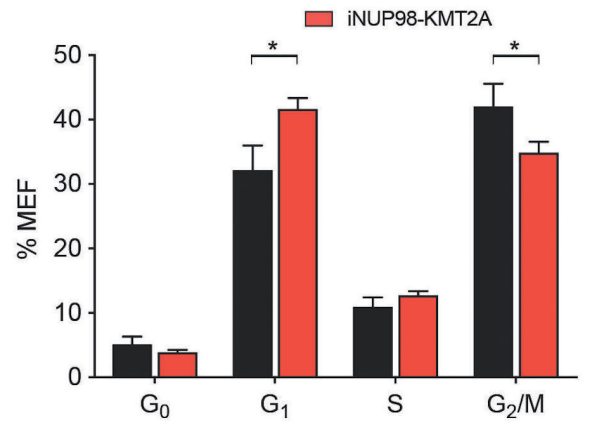

C
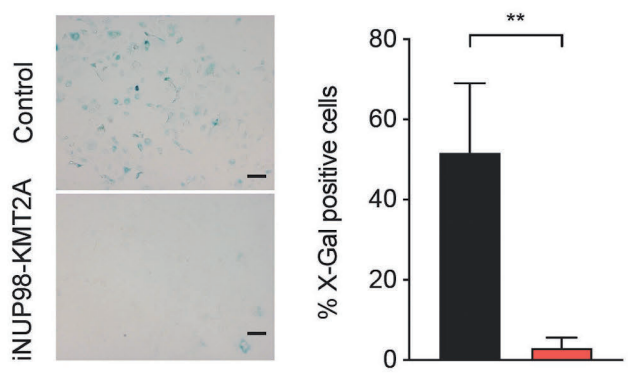

D

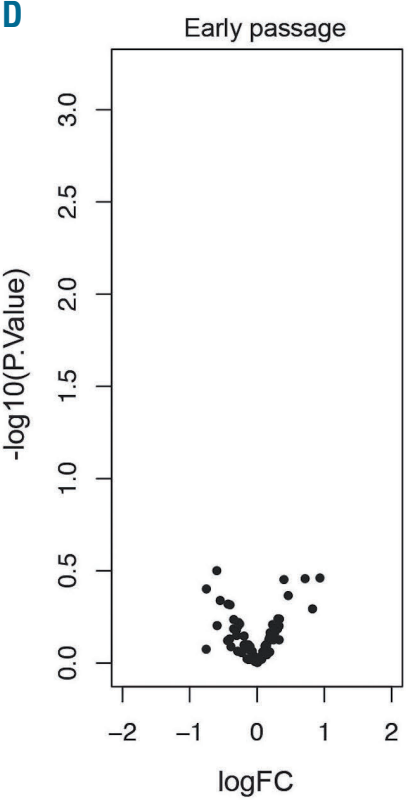

E

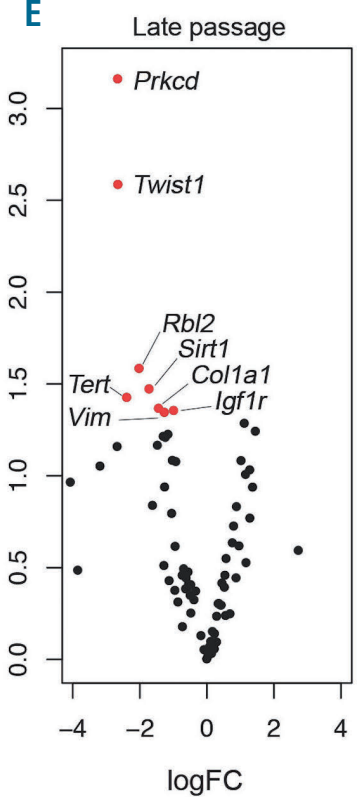

$\mathrm{F}$
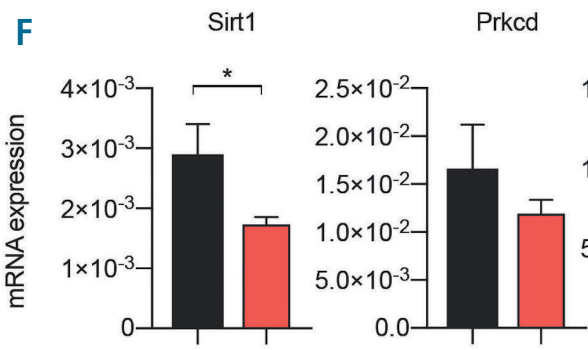

Prkcd

Twist1

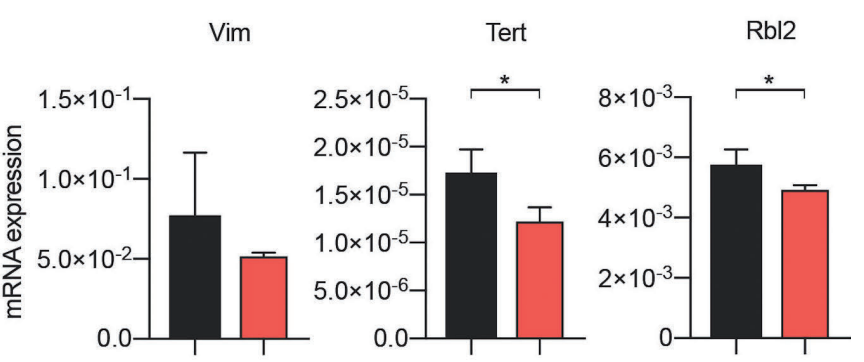

Figure 4. iNUP98-KMT2A expression impairs cell cycle progression of murine embryonic fibroblasts and bone marrow-derived hematopoietic stem and progenitor cells. (A) Murine embryonic fibroblasts (MEF), derived from iNUP98-KMT2A and wildtype (WT) control (CTRL) littermate mice were cultured in vitro in the presence of doxycycline (DOX) $(1 \mathrm{ug} / \mathrm{mL})$. iNUP98-KMT2A expression is shown relative to the level of GAPDH expression. * $P<0.05$, unpaired $t$-test, $\mathrm{n}=3$. (B) Flow cytometry-based

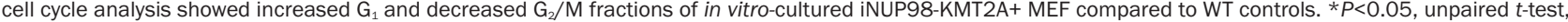
$\mathrm{n}=3$. (C) iNUP98-KMT2A and WT MEF cultured for eight passages in the presence of DOX $(1 \mu \mathrm{g} / \mathrm{mL})$ were stained for senescence-associated B-galactosidase activity with X-Gal (left panel). The number of X-Gal ${ }^{+}$cells in the culture was quantified (right panel). Images and counts are representative of three biological replicates. Scale bars: $100 \mathrm{um}$. ${ }^{*} P<0.01$, unpaired t-test, $\mathrm{n}=3$. (D) Differential mRNA expression from early (passages 1-2) and late (passages 8-10) passaged WT and iNUP98KMT2A MEF analyzed by a RT2 PCR array. Significant $(P<0.05)$ changes are highlighted in red. $(E)$ Validation of differentially expressed genes in MEF (Figure 4D) by quantitative polymerase chain reaction analysis in WT and iNUP98-KMT2A hematopoietic stem and progenitor cells after exposure to DOX ( $1 \mu \mathrm{g} / \mathrm{mL}$ ) in vitro for 48 h. *<0.05, unpaired $t$-test, $n=3$.

ly limit the generation of high-titer retroviral particles. We used a doxycycline-regulated transgenic expression system in which the rtTA is integrated into the ubiquitously expressed Rosa26 locus and the NUP98-KMT2A fusion is in the Hprt locus under control of a tet-responsive minimal promoter, previously used to model the impact of cellular origin in KMT2A-AF9 and KMT2AENL-driven leukemia. ${ }^{22,23,27}$

Secondary transplantation of iNUP98-KMT2A leukemic cells revealed that the inherent leakiness of the system might be sufficient to drive the phenotype in the absence of doxycycline after cellular selection in the mouse (Figure 3D) suggesting that, in contrast to KMT2AAF9 or KMT2A-ENL, low level NUP98-KMT2A transgene expression is sufficient to exert its oncogenic activity or that expression of the transgene might be required for ini- tial transformation but not for maintenance of neoplastic cells in all cases.

Retroviral expression, as well as constitutive or conditional activation, of many AML-associated fusions [involving the retinoic acid receptor alpha (RARA), core binding factor (CBF) or KMT2A] in the hematopoietic system of the mouse often closely phenocopies human disease. ${ }^{28,29}$ In most of these models, AML develops after a long latency without evidence of a symptomatic preleukemic MDS phase, with few exceptions such as the Vav1-promoter driven NUP98-HOXD13 fusion. ${ }^{30}$ NUP98HOXD13 mice developed T-cell leukemia, undifferentiated leukemia, megakaryocytic and erythroid leukemia or symptomatic MDS. In contrast, iNUP98-KMT2A mice (5 out of 22) only developed $\mathrm{Gr}-1^{+} / \mathrm{Mac}-1^{+} / \mathrm{c}-\mathrm{Kit}^{+} \mathrm{AML}$. Leukemic transformation of NUP98-HOXD13 mice was 


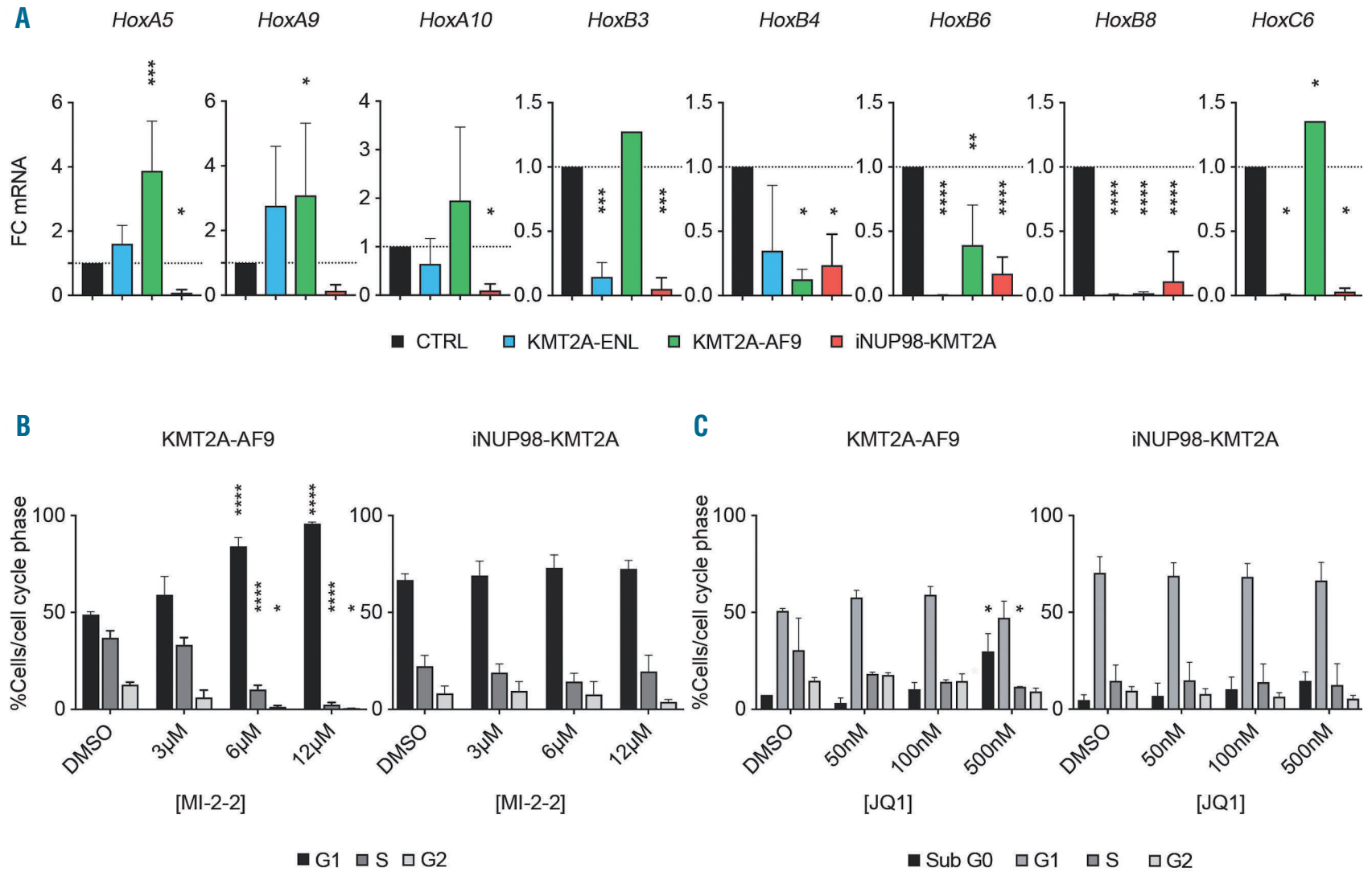

Figure 5. iNUP98-KMT2A acute myeloid leukemia cells express low levels of Hox genes and are resistant to small molecule menin and Brd4 inhibitors. (A) Expression of HoxA, $-B$, and $-C$ genes was quantified by quantitative polymerase chain reaction ( $\mathrm{PPCR}$ ) analysis in total bone marrow from wildtype (WT) control (CTRL) cells, leukemic cells from iNUP98-KMT2A mice as well as from mice transplanted with retrovirally-transduced KMT2A-ENL (rKMT2A-ENL) and rKMT2A-AF9 cells. Expression relative to that of WT cells is shown. $* P<0.05, * * P<0.01, * * * P<0.001, * * * * P<0.0001$, one-way analysis of variance (ANOVA) relative to control, $\mathrm{n}=3$. (B) rKMT2A-AF9 and iNUP98-KMT2A leukemic blasts were treated with the menin inhibitor, MI-2-2, for $48 \mathrm{~h}$ at the indicated concentrations and the cell cycle phase was analyzed by flow cytometry. The figure shows the percentage of cells in each phase of the cell cycle. $* P<0.05, * * P<0.01, * * * P<0.001, * * * * P<0.0001$, twoway ANOVA relative to cells treated with dimethylsulfoxide (DMSO), $n=2$. (C) rKMT2A-AF9 and iNUP98-KMT2A leukemic blasts were treated with the BRD4 inhibitor JQ1, for $48 \mathrm{~h}$ at the indicated concentrations. Cell cycle phase was analyzed by flow cytometry. The figure shows the percentage of cells in each phase of the cell cycle. ${ }^{*} P<0.05$, two-way ANOVA relative to DMSO-treated cells, $\mathrm{n}=2$.

accompanied by spontaneous mutations in Nras, Kras and Cbl; however, no such mutations were found in three iNUP98-KMT2A mice that developed $\mathrm{AML}^{31}$ (data not shown). Several studies also demonstrated leukemogenic cooperation of NUP98-HOXD13 with overexpression of Meis1, MN1, or loss of $p 53$ or $p 15^{\text {INK4B }} .^{2-35}$ Intercrossing of transgenic NUP98-HOXD13 mice with Flt3-internal tandem duplication (ITD) knock-in mice resulted in acceleration to a fully-penetrant AML phenotype. ${ }^{36}$ In contrast to NUP98-HOXD13, we observed that transplantation of iNUP98-KMT2A BM cells retrovirally overexpressing FLT3-ITD did not accelerate the disease (data not shown). ${ }^{36}$

In the presence or absence of FLT3-ITD, pre-leukemic NUP98-HOXD13 cells expressed significantly increased levels of HoxA7, HoxA9, HoxB4, HoxB6, HoxB7, HoxC4 and HoxC6 mRNA ${ }^{30,36}$ In sharp contrast, BM cells from diseased iNUP98-KMT2A mice expressed significantly reduced levels of the HoxA-B-C gene cluster compared to normal BM cells, recapitulating what was shown in primary NUP98KMT2A ${ }^{+}$AML cells. ${ }^{19}$ Expression levels of HoxA-B-C genes below those observed in normal HSPC suggest that the iNUP98-KMT2A fusion may affect the function of normal KMT2A in a dominant-negative manner.
Previous work showed that KMT2A plays a critical role in cell cycle progression. ${ }^{37}$ Interestingly, under baseline conditions, we found a higher proportion of iNUP98-KMT2A Lin cells in S-phase when compared to WT cells supporting previous studies indicating that ablation of normal KMT2A function results in defective S-phase cell cycle entry. The percentage of both WT and iNUP98-KMT2A cells in S-phase decreased following exposure to ionizing radiation (data not shown) as has been demonstrated previously. ${ }^{38}$ Interestingly, compared to control cells, in vitro doxycycline treatment of both iNUP98-KMT2A BM-derived HSPC and MEF led to the accumulation of cells in the $\mathrm{G}_{1}$-phase, mirroring what was seen in LSK cells taken from iNUP98-KMT2A mice that had been on doxycycline food for several months. Further experiments with MEF showed that expression of iNUP98-KMT2A abrogated cellular senescence: compared to WT cells, iNUP98-KMT2A MEF on doxycycline never showed any signs of crisis and could easily be propagated for $>45$ passages. In contrast, iNUP98KMT2A cells off doxycycline showed signs of a crisis at passages 10-12 but were able to escape and could also be propagated for over 40 passages (data not shown), suggesting that very low expression of iNUP98-KMT2A is suffi- 
cient to provide the cells the signals to escape apoptosis after crisis.

Among the genes downregulated in late passage iNUP98-KMT2A relative to control MEF, many have been implicated in cell cycle- or senescence-regulatory capacities. Previously, sirtuin1 (sirt1)-deficient MEF were shown to be resistant to replicative senescence through a p53-dependent mechanism; $;^{39}$ there is also evidence to suggest that Sirt1 plays a crucial role in Foxo3-activated cell cycle arrest. ${ }^{40}$ It has been shown that the insulin-like growth factor 1 receptor (IGF1R) ligand, insulin-like growth factor (IGF1), is involved in cellular senescence control through the Sirt1-p53 axis, ${ }^{41}$ in line with a proposed model whereby p53-dependent cellular senescence is counteracted by inhibition of IGF1R signaling. ${ }^{42}$ In a lung fibroblast cell model, Rbl2 (p130) expression was increased along with E2F-4 and markers of cellular senescence following heat shock protein-27 (HSP27) knock-down. Inhibition of Rbl2 counteracted the effects of HSP27 knock-down and significantly reduced senescence-associated $\beta$-galactosidase staining in a p53-independent manner. ${ }^{43}$ Additionally, the ribonuclease polymerase Tert (telomerase reverse transcriptase), which maintains telomeric ends, has a well-demonstrated role in resisting senescence; however, some primary tumor samples have tested negative for telomerase activity ${ }^{44}$ and alternative mechanisms to overcome replicationassociated telomeric shortening have been proposed with evidence for alternative lengthening of telomeres in $10-15 \%$ of cancers ${ }^{45}$ Finally, the role of protein kinase C delta (Prkcd) in senescence is currently poorly understood, but studies have suggested that Prkcd is an important mediator of transforming growth factor- $\beta$-induced senescence. ${ }^{46}$

Peptides and small molecule antagonists of KMT2Amenin/LEDGF interactions have been shown to reduce the transforming activity of KMT2A fusions by interfering with binding to targets, including the $H O X-A$ gene cluster. ${ }^{5-10} \mathrm{It}$ has been shown that leukemic transformation by NUP98 fusions is KMT2A-dependent; ${ }^{14}$ this would support the idea that iNUP98-KMT2A AML cells are susceptible to small molecules targeting the N-terminus of WT KMT2A. Conversely, the lack of the menin/LEDGF interaction site would predict poor sensitivity of iNUP98-KMT2A AML cells to these compounds. Indeed, compared to KMT2AAF9-driven cells, iNUP98-KMT2A leukemic cells were resistant to blockade of the KMT2A-menin interaction by the small molecule MI-2-2 at concentrations previously demonstrated to inhibit growth of human KMT2A-AF4 and murine KMT2A-AF9 transformed cells. ${ }^{12,47}$ iNUP98KMT2A AML cells also showed a reduced sensitivity to the BET-bromodomain inhibitor JQ1, which interferes with active transcription and elongation through displacement of BRD4 from chromatin, ${ }^{48}$ while challenge of KMT2A-AF9 cells recapitulated published growth inhibition. ${ }^{26}$ This suggests that targeting KMT2A might not be suitable for efficient therapeutic interference with NUP98-KMT2A AML.

\section{Acknowledgments}

The authors thank Danny Labes, Telma Lopes, Emmanuel Traunecker, and Lorenzo Raeli from the University of Basel Flow Cytometry Facility; Nicole Meier and the members of the Animal Care Facility at the University of Basel; Masao Seto for the full-length human KMT2A mRNA; Michael Kyba for providing the A2Lox-Cre ES cells; and Patrick Kopp and JeanFrançoise Spetz for their assistance generating the iNUP98KMT2A mice.

\section{Funding}

JS's laboratory was supported by: grants from Swiss Cancer Research (KFS-4258-08-2017, KFS-3487-08-2014) and the Swiss National Science Foundation (SNF, 31003_A 173224/1). $A P$ was supported by the Novartis Research Foundation. Basel, Switzerland.

\section{References}

1. Gough SM, Slape CI, Aplan PD. NUP98 gene fusions and hematopoietic malignancies: common themes and new biologic insights. Blood. 2011;118(24):6247-6257.

2. Takeda A, Yaseen NR. Nucleoporins and nucleocytoplasmic transport in hematologic malignancies. Semi Cancer Biol. 2014;27:310.

3. Muntean AG, Hess JL. The pathogenesis of mixed-lineage leukemia. Annu Rev Pathol. 2012;7:283-301.

4. de Boer J, Walf-Vorderwulbecke V, Williams O. In focus: MLL-rearranged leukemia. Leukemia. 2013;27(6):1224-1228.

5. Yokoyama A. Transcriptional activation by MLL fusion proteins in leukemogenesis. Exp Hematol. 2016;46:21-30

6. Slany RK. The molecular mechanics of mixed lineage leukemia. Oncogene. 2016; 35:5215-5223.

7. Murai MJ, Chruszcz M, Reddy G, Grembecka J, Cierpicki T. Crystal structure of menin reveals binding site for mixed lineage leukemia (MLL) protein. J Biol Chem. 2011;286(36):31742-31748.

8. Huang J, Gurung B, Wan B, et al. The same pocket in menin binds both MLL and JUND but has opposite effects on transcription. Nature. 2012;482(7386):542-546.

9. Yokoyama A, Somervaille TC, Smith KS Rozenblatt-Rosen $\mathrm{O}$, Meyerson M, Cleary ML. The menin tumor suppressor protein is an essential oncogenic cofactor for MLLassociated leukemogenesis. Cell. 2005;123 (2):207-218.

10. Yokoyama A, Cleary ML. Menin critically links MLL proteins with LEDGF on cancerassociated target genes. Cancer Cell. 2008;14(1):36-46.

11. Grembecka J, He S, Shi A, et al. Menin-MLL inhibitors reverse oncogenic activity of MLL fusion proteins in leukemia. Nat Chem Biol. 2012;8(3):277-284.

12. Borkin D, Pollock J, Kempinska K, et al. Property focused structure-based optimization of small molecule inhibitors of the protein-protein interaction between menin and mixed lineage leukemia (MLL). J Med Chem. 2016:59(3):892-913.

13. Pascual-Garcia P, Jeong J, Capelson M Nucleoporin Nup98 associates with Trx/MLL and NSL histone-modifying complexes and regulates Hox gene expression. Cell Rep. 2014;9(2):433-442.

14. Xu H, Valerio DG, Eisold ME, et al. NUP98 fusion proteins interact with the NSL and MLL1 complexes to drive leukemogenesis. Cancer Cell. 2016;30(6):863-878.

15. Shima Y, Yumoto M, Katsumoto $T$, Kitabayashi I. MLL is essential for NUP98HOXA9-induced leukemia. Leukemia. 2017;31(10):2200-2210

16. Mitani K, Sato Y, Hayashi Y, et al. Two myelodysplastic syndrome cases with the inv(11)(p15q23) as a sole chromosomal abnormality. Br J Haematol. 1992;81(4):512515

17. Inaba T, Hayashi Y, Hanada R, Nakashima M, Yamamoto K, Nishida T. Childhood myelodysplastic syndromes with $11 \mathrm{p} 15$ translocation. Cancer Genet Cytogenet. 1988;34(1):41-46.

18. Calabrese G, Fantasia D, Spadano A, Morizio E, Di Bartolomeo P, Palka G. Karyotype refinement in five patients with acute myeloid leukemia using spectral karyotyping. Haematologica. 2000;85(11):1219-1221.

19. Kaltenbach S, Soler G, Barin C, et al. NUP98MLL fusion in human acute myeloblastic leukemia. Blood. 2010;116(13):2332-2335.

20. Huret JL. $\mathrm{t}(17 ; 20)(\mathrm{q} 21 ; \mathrm{q} 11)$. Atlas Genet Cytogenet Oncol Haematol. 2018;2:51.

21. Joh T, Kagami Y, Yamamoto $K$, et al. Identification of MLL and chimeric MLL 
gene products involved in 11q23 translocation and possible mechanisms of leukemogenesis by MLL truncation. Oncogene. 1996;13(9):1945-1953.

22. Iacovino $M$, Hernandez $C, X u Z$, Bajwa G, Prather M, Kyba M. A conserved role for Hox paralog group 4 in regulation of hematopoietic progenitors. Stem Cells Dev. 2009;18(5):783-792.

23. Stavropoulou V, Kaspar S, Brault L, et al. MLL-AF9 expression in hematopoietic stem cells drives a highly invasive AML expressing EMT-related genes linked to poor outcome. Cancer Cell. 2016;30(1):43-58.

24. Thanasopoulou A, Tzankov A, Schwaller J. Potent co-operation between the NUP98NSD1 fusion and the FLT3-ITD mutation in acute myeloid leukemia induction. Haematologica. 2014;99(9):1465-1471.

25. Franks TM, McCloskey A, Shokirev MN, Benner C, Rathore A, Hetzer MW. Nup98 recruits the Wdr82-Set1A/COMPASS complex to promoters to regulate H3K4 trimethylation in hematopoietic progenitor cells. Genes Dev. 2017;31(22):2222-2234.

26. Zuber J, Shi J, Wang E, et al. RNAi screen identifies Brd4 as a therapeutic target in acute myeloid leukaemia. Nature. 2011;478(7370):524-528.

27. Stavropoulou V, Almosailleakh M, Royo $\mathrm{H}$, et al. A novel inducible mouse model of MLL-ENL-driven mixed-lineage acute leukemia. HemaSphere. 2018;2(4):e51.

28. Milne TA. Mouse models of MLL leukemia: recapitulating the human disease. Blood. 2017;129(16):2217-2223.

29. Fisher JN, Stavropoulou V, Kalleda N, Schwaller J. The impact of the cellular origin in acute myeloid leukemia: learning from mouse models. Hemasphere. 2019;3(1): e152.

30. Lin YW, Slape C, Zhang Z, Aplan PD.
NUP98-HOXD13 transgenic mice develop a highly penetrant, severe myelodysplastic syndrome that progresses to acute leukemia. Blood. 2005;106(1):287-295

31. Slape C, Liu LY, Beachy S, Aplan PD Leukemic transformation in mice expressing a NUP98-HOXD13 transgene is accompanied by spontaneous mutations in Nras, Kras, and Cbl. Blood. 2008;112(5):20172019

32. Pineault N, Buske C, Feuring-Buske M, et al. Induction of acute myeloid leukemia in mice by the human leukemia-specific fusion gene NUP98-HOXD13 in concert with Meis1. Blood. 2003;101(11):4529-4538.

33. Slape C, Hartung H, Lin YW, Bies J, Wolff $\mathrm{L}$, Aplan PD. Retroviral insertional mutagenesis identifies genes that collaborate with NUP98-HOXD13 during leukemic transformation. Cancer Res. 2007;67(11):5148 5155.

34. Humeniuk R, Koller R, Bies J, Aplan P, Wolff L. Brief report: loss of $\mathrm{p} 15 \mathrm{Ink} 4 \mathrm{~b}$ accelerates development of myeloid neoplasms in Nup98-HoxD13 transgenic mice. Stem Cells. 2014;32(5):1361-1366.

35. Imren $S$, Heuser $M$, Gasparetto $M$, et al. Modeling de novo leukemogenesis from human cord blood with MN1 and NUP98HOXD13. Blood. 2014;124(24):36083612 .

36. Greenblatt S, Li L, Slape C, et al. Knock-in of a FLT3/ITD mutation cooperates with a NUP98-HOXD13 fusion to generate acute myeloid leukemia in a mouse model. Blood. 2012:119(12):2883-2894.

37. Liu H, Cheng EH, Hsieh JJ. Bimodal degradation of MLL by SCFSkp2 and APCCdc20 assures cell cycle execution: a critical regulatory circuit lost in leukemogenic MLL fusions. Genes Dev. 2007;21(19):2385-2398.

38. Liu $\mathrm{H}$, Takeda $\mathrm{S}$, Kumar $\mathrm{R}$, et al
Phosphorylation of MLL by ATR is required for execution of mammalian S-phase check point. Nature. 2010;467(7313):343-346.

39. Chua KF, Mostoslavsky R, Lombard DB, et al. Mammalian SIRT1 limits replicative life span in response to chronic genotoxic stress. Cell Metab. 2005;2(1):67-76.

40. Brunet A, Sweeney LB, Sturgill JF, et al Stress-dependent regulation of FOXO transcription factors by the SIRT1 deacetylase. Science. 2004;303(5666):2011-2015.

41. Tran D, Bergholz J, Zhang $\mathrm{H}$, et al. Insulinlike growth factor-1 regulates the SIRT1-p53 pathway in cellular senescence. Aging Cell 2014;13(4):669-678

42. Duan L, Maki CG. The IGF-1R/AKT pathway determines cell fate in response to p53 Transl Cancer Res. 2016;5(6):664-675.

43. Park AM, Tsunoda I, Yoshie O. Heat shock protein 27 promotes cell cycle progression by down-regulating E2F transcription factor 4 and retinoblastoma family protein $\mathrm{p} 130$. J Biol Chem. 2018;293(41):15815-15826.

44. Kim NW, Piatyszek MA, Prowse KR, et al Specific association of human telomerase activity with immortal cells and cancer Science. 1994;266(5193):2011-2015.

45. Cesare AJ, Reddel RR. Alternative lengthening of telomeres: models, mechanisms and implications. Nat Rev Genet. 2010;11 (5):319-330

46. Katakura Y, Udono $\mathrm{M}$, Katsuki $\mathrm{K}$, et al Protein kinase $\mathrm{C}$ delta plays a key role in cellular senescence programs of human normal diploid cells. J Biochem. 2009;146(1):87-93.

47. Shi A, Murai MJ, He S, et al. Structural insights into inhibition of the bivalent menin-MLL interaction by small molecules in leukemia. Blood. 2012;120(23):4461-4469.

48. Filippakopoulos P, Oi J, Picaud S, et al Selective inhibition of BET bromodomains. Nature. 2010;468(7327):1067-1073. 